\title{
Determinants of malaria infection in Dembia district, Northwest Ethiopia: a case-control study
}

\author{
Fisseha Agegnehu', Alemayehu Shimeka ${ }^{2}$, Firnus Berihun ${ }^{3}$ and Melkamu Tamir ${ }^{4^{*}}$
}

\begin{abstract}
Background: Despite the progress in reducing malaria infections and related deaths, the disease remains a major global public health problem. The problem is among the top five leading causes of outpatient visits in Dembia district of the northwest Ethiopia. Therefore, this study aimed to assess the determinants of malaria infections in the district.

Methods: An institution-based case-control study was conducted in Dembia district from October to November 2016. Out of the ten health centers in the district, four were randomly selected for the study in which 370 participants (185 cases and 185 controls) were enrolled. Data were collected using a pretested structured questionnaire. Factors associated with malaria infections were determined using logistic regression analysis. Odds ratio with $95 \% \mathrm{Cl}$ was used as a measure of association, and variables with a $p$-value of $\leq 0.05$ were considered as statistically significant.

Results: The median age of all participants was 26 years, while that of cases and controls was 22 and 30 with a range of 1 to 80 and 2 to 71 , respectively. In the multivariable logistic regression, over 15 years of age adjusted odds ratio(AOR) and confidence interval (Cl) of ( $\mathrm{AOR}=18 ; 95 \% \mathrm{Cl}: 2.1,161.5)$, being male ( $\mathrm{AOR}=2.2 ; 95 \% \mathrm{Cl}: 1.2,3.9)$, outdoor activities at night $(A O R=5.7 ; 95 \% \mathrm{Cl}: 2.5,12.7)$, bed net sharing (AOR $=3.9 ; 95 \% \mathrm{Cl}: 2.0,7.7)$, and proximity to stagnant water sources (AOR $=2$. 7; $95 \% \mathrm{Cl}: 1.3,5.4)$ were independent predictors.

Conclusion: Being in over 15 years of age group, male gender, night time activity, bed net sharing and proximity to stagnant water sources were determinant factors of malaria infection in Dembia district. Additional interventions and strategies which focus on men, outdoor work at night, household net utilization, and nearby stagnant water sources are essential to reduce malaria infections in the area.
\end{abstract}

Keywords: Malaria, Determinant factors, Case-control study

\section{Background}

Malaria, which is one of the leading causes of illness and death in the world, is caused by protozoan parasites of the genus plasmodium. About $44 \%$ of the world's population is at risk of malaria infection and over 97 countries are affected by the disease. There are 216 million cases and 445, 000 malaria caused deaths worldwide, and the African Region accounts for about $90 \%$ of the cases and deaths. Furthermore, 14 sub-Saharan African countries and India carried $80 \%$ of the global malaria burden [1].

\footnotetext{
* Correspondence: mtamir082@gmail.com

${ }^{4}$ Departement of Human Nutrition, College of Medicine and Health Sciences, University of Gondar, Gondar, Ethiopia

Full list of author information is available at the end of the article
}

Despite the progress gained in reducing malarial morbidity and mortality, the disease remains a major public health problem in many countries of the world. The World Health Organization (WHO) report shows that the number of malaria cases globally fell from the estimated 237 million in 2010 to 216 million in 2016, a decline of $18 \%$. Most of the cases were estimated to have occurred in the African Region (90\%), followed by Southeast Asia (7\%) and the East Mediterranean Region (2\%). Moreover, the number of malarial deaths globally fell from the estimated 446, 000 in 2015 to 445, 000 in 2016 [2].

Malaria is one of the main public health problems in Ethiopia; approximately $75 \%$ of the landmass is malariaendemic, and $65 \%$ of the population is at risk of malaria 
infection [3]. According to the Ethiopian Federal Ministry of Health, malaria accounted for $15 \%$ of the reported outpatient visits and nearly $15 \%$ of the admissions in the country. Furthermore, malaria is among the ten leading causes of inpatient deaths among children less than 5 years of age [4]. A total of 1,127,241 cases of malaria were reported in Amhara Region; 404,926 and 225,818 of these were in West Gojjam and North Gondar zones, respectively [4].

Dembia is one of the most affected districts in the region. Its proximity to the Lake Tana basin (the largest lake in Ethiopia) and high altitude (2000 m above sea level) are the major factors for the endemicity [5]. In 2016, about 138,842 long lasting insecticidal nets (LLINs) were distributed, and 16 kebeles (lowest administrative units) were sprayed. However, the burden of the disease kept increasing; for instance, in over a 46-week interval, 22,166 malaria cases were reported in 2016 in contrast to 10,415 in 2015 [6].

Malaria prevention and control interventions that included mass distribution of LLINs, the scaled up of indoor residual spraying (IRS), the introduction of rapid diagnostic tests (RDTs) at community levels, and the adoption of artemisinin-based combination therapies (ACTs) have been scaled up since 2005, leading to the reduction of the burden of the disease by about $50 \%$, on average [7].

The national malaria indicator survey demonstrates that in Amhara Region the coverage of LLIN and/or IRS increased from 76.2 in 2007 to $86.3 \%$ in 2011 and community knowledge of malaria $26.7 \%$ to $48.4 \%$ in the same period [8]. Even though written data on malaria cases were limited in the health centers in Dembia district, according to the annual performance report of the FMOH 2017, the total malaria cases treated in the health facilities were 1,820,967 [9].

The burden of malaria remains a major public health problem in Dembia district despite the interventions implemented. Therefore, the aim of this study was to identify the determinants of malaria infections in the district.

\section{Methods}

\section{Study design and setting}

An institution-based matched case-control study was conducted from October to November 2016. The study was conducted in Dembia district, Amhara Region, northwest Ethiopia. It is located in North Gondar zone $729 \mathrm{~km}$ north of Addis Ababa at $12^{\circ} 18^{\prime} 30^{\prime \prime} \mathrm{N}$ and $37^{\circ} 17^{\prime}$ $30^{\prime \prime} \mathrm{E}$. The district has an area of $148,968 \mathrm{sq}$. $\mathrm{km}$ with a total population of 307,967 . Out of the total area of the district, plain land accounts for about $87 \%$, mountains and hills $5 \%$, valleys and gorges $4.8 \%$, and water bodies $3.2 \%$. The altitude of the district ranges from 1850 to $2000 \mathrm{~m}$ above sea level. The district receives an annual rainfall of 700 to $1160 \mathrm{~mm}$ on average [10]. There are 10 health centers and 40 health posts in the district providing healthcare services, such as health education, diagnosis, and treatment (Fig. 1).

The district is divided into 45 sub-districts called Kebeles, the lowest administrative units of Ethiopia. Malaria intervention based on its prevalence is targeted in 16 sub-districts for IRS and the rest for ITN distribution.

Study design and period: An institution-based matched case-control study was conducted from October to November 2016.

Source population: All individuals living in Dembia district were considered as the source population.

Study population: All permanent residents of the districts visiting the health centers.

\section{Sample size and sampling technique}

The sample size for case control study was calculated using the following formula:

$$
\frac{r+1}{r} \frac{(p *)(1-p *)(z \beta+z a / 2) 2}{(p 1-p 2) 2}
$$

Alternatively, Epi-Info software (matched case-control) method with a p1 (95\%), p2 86.3\% of ITN/IRS exposure among controls [11], $r(1), \mathrm{OR}(3), \mathrm{z \alpha} / 2(95 \%)$ and $\mathrm{Z1}-\beta(80 \%)$ was used to calculate the sample size. Accordingly, $\mathrm{n} 1$ was 196 malaria-infected patients, whereas n2 was 196, making a total of 392 participants.

Assuming that all of the health centers were likely to be homogeneous and visited by an equal number of cases, we selected 93 participants each from the four health centers of Dembia district in Ethiopia. We collected data from cases and controls in the four selected health centers for an average of 1 month.

\section{Case definition}

Cases were confirmed malaria infected individuals confirmed by microscopy or RDT testes (Care Start ${ }^{\circ}$, Access Bio, NJ, USA) at the selected health centers from October 1 to November 10, 2016.

Controls were individuals presenting at the same health centers free from malaria infection as diagnosed by microscopy or RDT tests.

\section{Inclusion criteria}

We included permanent residents of the district who visited the health centers and screened for malaria infection using microscopy and RDT tests.

\section{Exclusion criteria}

Participants unable to provide the required information due to different conditions, like extreme illness and absence of caregivers were excluded. 


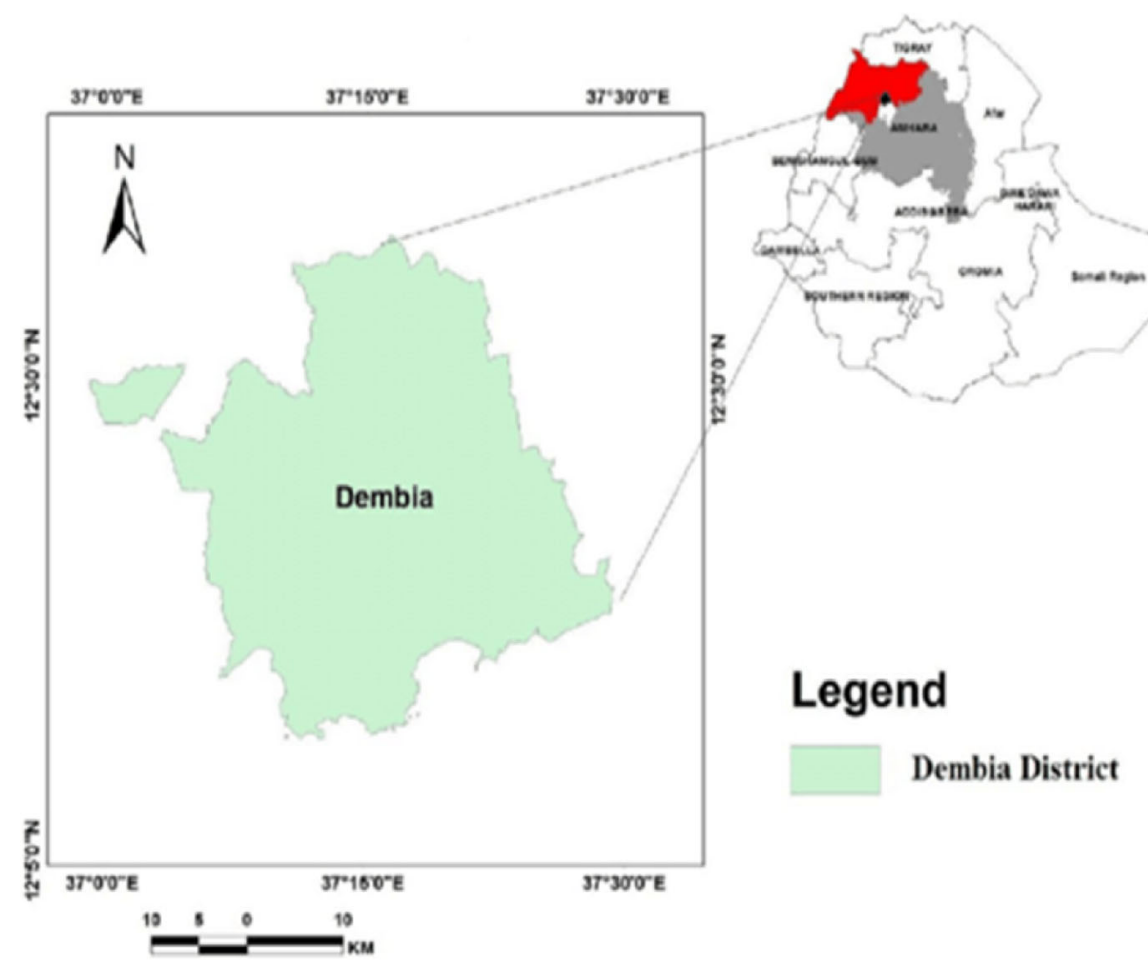

Fig. 1 Location of the study area, Dembia district, Northwest Ethiopia (source: Ethio-Geographic Information System (GIS) and (CSA, 2007)

\section{Study variables}

\section{Dependent variable}

The dependent variable was malaria infection among health center attendants.

\section{Independent variables}

Socio-demographic variables: gender, age, marital status, educational status, ethnicity, occupation, family size.

Materials used for malaria prevention related variables: ITN possession, IRS, number of persons sharing a net.

Environment-related variables: housing condition, surrounding water bodies, water source for domestic use.

Personal activity-related variables: sleeping outdoors at night, travel history to other malaria endemic areas, sleeping sites.

Knowledge: about causes and ways of malaria prevention.

\section{Data collection procedure}

An interviewer-administered questionnaire was employed on infected individuals in the selected health centers in the district to get primary data on demographics and potential risk factors, such as socio-demography, knowledge about malaria, environmental factors, and use of malaria prevention measures. The same questionnaire was used to collect data on potential predictors from the control group. Cases were selected based on definitions developed after they completed their examination (exit interview), and patient cards were immediately taken from the examiner to link the results of the diagnosis. Then, they were interviewed for other relevant bits of information. After the recruitment of cases, controls who lived in the same areas as cases were included.

\section{Data quality control}

The data collection tool was first prepared in English and translated to the local language, Amharic and back translated to English to cheek for consistency. Pre-test was done on $5 \%$ of the respondents prior to the actual data collection in a neighboring district. Training was given forboth data collectors and supervisor on the data collection tools and techniques of interviewing with practical exercises. Daily supervision was done by the supervisor and principal investigator.

\section{Data processing and analysis}

Data was cleaned for completeness and consistencies, coded and entered in to Epi info version 7.0 and transported into the Statistical Package for the Social Sciences (SPSS) version 20 for further analysis. The results were organized, summarized and presented using texts, tables, and graphs.

Crude odds ratios (COR) with a 95\% confidence interval (CI) were estimated in the bi-variable logistic regression analysis to screen the effect each independent 
variable on the outcome variable and to select candidate variables for the multi-variable logistic regression analysis. Because of a relatively large number of independent variables considered, we had to screen them using bi-variable analysis to minimize the chance of multicollinearity in the multi-variable regression. Thus, only independent variables with a $p$-value of 0.20 or less in the bivariable logistic regression were included in the multivariable logistic regression to get the adjusted effect of each covariate.

Variables which were significant at p-value 0.05 level and $95 \% \mathrm{CI}$ in the multivariable logistic regression analysis were considered to be the determinant factors of malaria infections.

\section{Results}

\section{Characteristics of the study population}

The median age of all participants was 26 years, while that of cases and controls was 22 and 30 with a range of 1 to 80 and 2 to 71 , respectively. The cases group contained more men than women, $74 \%$ and $26 \%$, respectively. More than one-third of the participants, 175 (37\%) , were farmers, that is, agriculture was the main source of income for $98 \%$ of the cases and $85 \%$ of the controls (Table 1).

The majority (85\%) of the participants had bed nets, and about one-third of the houses $(27 \%)$ were treated with IRS in the previous 6 months. Most of the houses (98\%) were constructed of mud walls. The sleeping sites of a large proportion (66\%) of the respondents were beds without mattresses, and most of (89\% cases and 95\% controls) the respondents used bed nets consistently (Table 2).

\section{Knowledge of participants about causes and preventions of malaria}

Cases and controls had comparable knowledge about the causes and preventions of malaria. Most of the respondents (98\% of either group) heard about malaria through various means of communication.

Respondents in each group, that is, $87 \%$ of the cases and $94 \%$ of the controls at least knew that the mosquito was one of the causes of malaria. On the other hand, $84 \%$ of the cases and $78 \%$ of the controls wrongly held that malaria was acquired either by getting soaked in rain, eating immature sugarcane or contaminated food or by drinking contaminated water. According to $93 \%$ of the cases and $94 \%$ of the controls, sleeping under any types of bed net was the most common method of preventing malaria (Table 3 ).

\section{Determinants of malaria infection}

In the bivariable logistic regression, gender, age, outdoor activities at night, travel history in the past 2 weeks to other malarious area, habit of sleeping outdoors at night, self reported bed net use, proximity to stagnant water and a temporary river body, and number of persons sharing a bed net were statistically significantly associated with malaria infection at a $p$-value of 0.2. All these variables were included in the multivariable logistic regression model, but other variables which had a $p$-value greater than 0.2 in this model were not included in the multivariable regression model.

Table 1 Socio-demographic characteristics of respondents in Dembia district, northwest Ethiopia, $2016(N=370)$

\begin{tabular}{|c|c|c|c|}
\hline \multirow[t]{2}{*}{ Variable } & & \multirow{2}{*}{$\begin{array}{l}\text { Case } \\
N=185(\%)\end{array}$} & \multirow{2}{*}{$\begin{array}{l}\text { Control } \\
N=185(\%)\end{array}$} \\
\hline & & & \\
\hline \multirow[t]{2}{*}{ Educational status of respondents } & No formal education & $116(63)$ & $115(63)$ \\
\hline & Primary and above & $69(37)$ & $67(37)$ \\
\hline \multirow[t]{2}{*}{ Educational status of household head } & No formal education & 165(91) & $142(78)$ \\
\hline & Primary and above & $17(9)$ & $41(22)$ \\
\hline \multirow[t]{3}{*}{ Marital status } & Married & $91(49)$ & $127(69)$ \\
\hline & Single & $92(50)$ & $56(31)$ \\
\hline & Divorced/separated/widowed & $2(1)$ & $0(0)$ \\
\hline Family size & Mean(range) & $5.4(1-12)$ & $5.1(1-12)$ \\
\hline \multirow[t]{2}{*}{ Sex } & Female & $48(26)$ & $100(54)$ \\
\hline & Male & $137(74)$ & $85(46)$ \\
\hline Age & Median(range) & $22(1-80)$ & $30(2-71)$ \\
\hline \multirow[t]{4}{*}{ Occupation } & Farmer & $93(51)$ & $83(45)$ \\
\hline & Student & $46(26)$ & $24(13)$ \\
\hline & Housewife & $21(12)$ & $65(35)$ \\
\hline & Private & 20(11) & $33(17)$ \\
\hline
\end{tabular}


Table 2 Housing condition, water source for domestic use, and malaria infection in Dembia district, Northwest Ethiopia, 2016 ( $N=$ 370)

\begin{tabular}{|c|c|c|c|}
\hline \multirow[t]{2}{*}{ Variables } & \multirow[t]{2}{*}{ Description } & \multirow{2}{*}{$\begin{array}{l}\text { Case } \\
N=185(\%)\end{array}$} & \multirow{2}{*}{$\begin{array}{l}\text { Control } \\
N=185(\%)\end{array}$} \\
\hline & & & \\
\hline \multirow[t]{2}{*}{ Main material of the room's wall } & Mud & 182(99) & 180(98) \\
\hline & Wood plunk & $2(1)$ & $3(2)$ \\
\hline \multirow[t]{3}{*}{ Main material of room's window } & Metallic & $9(5)$ & $11(6)$ \\
\hline & Wooden & $120(65)$ & $127(69)$ \\
\hline & No window & $55(30)$ & $47(25)$ \\
\hline \multirow[t]{3}{*}{ Main material of the room's floor } & Cement & $0(0)$ & $2(1)$ \\
\hline & Earth & $46(25)$ & $36(19)$ \\
\hline & Local dung & $138(75)$ & $146(80)$ \\
\hline \multirow[t]{3}{*}{ Sleeping sites } & Bed with mattress & $43(23)$ & $67(36)$ \\
\hline & Bed without mattress & $136(74)$ & $110(60)$ \\
\hline & Floor & $6(3)$ & $8(4)$ \\
\hline \multirow[t]{2}{*}{ Household bed net possession } & Yes & $152(82)$ & $161(87)$ \\
\hline & No & $33(18)$ & $24(13)$ \\
\hline \multirow[t]{2}{*}{ Indoor residual spraying } & Yes & $52(28)$ & $47(26)$ \\
\hline & No & $132(72)$ & $137(74)$ \\
\hline \multirow[t]{2}{*}{ Bed net utilization } & Yes & $137(89)$ & 153(95) \\
\hline & No & $17(11)$ & $8(5)$ \\
\hline
\end{tabular}

When each independent variable was adjusted for other variables, age, gender, sleeping outdoors at night, proximity to stagnant water, and bed net use were found to be statistically significantly associated with malaria infection at a 95\% confidence level and a p-value of 0.05 .

Age greater than 15 years with an adjusted odds ratio(AOR) and confidence interval $(\mathrm{CI})(\mathrm{AOR}=18$; $95 \%$
CI: 2.1-161.5), male (AOR $=2.2$; 95\%CI: $1.2-3.9)$, staying outside at night ( $\mathrm{AOR}=5.7 ; 95 \% \mathrm{CI}$ : $2.5-12.7$ ), proximity to stagnant water $(\mathrm{AOR}=2.7 ; 95 \% \mathrm{CI}$ : $1.3-5.4)$, and three or more people sharing one net had more risk for malaria infection than those sharing one net with two people $(\mathrm{AOR}=3.9 ; 95 \% \mathrm{CI}: 2.0-7.7)$. Variables, such as proximity to temporary river bodies, travel history to

Table 3 Knowledge on cause and prevention of malaria infection among residents of Dembia district, northwest Ethiopia, $2016(N=370)$

\begin{tabular}{|c|c|c|c|}
\hline \multirow[t]{2}{*}{ Variables } & \multirow[t]{2}{*}{ Category } & Cases & \multirow{2}{*}{$\begin{array}{l}\text { Control } \\
N(\%)\end{array}$} \\
\hline & & $N(\%)$ & \\
\hline \multirow[t]{2}{*}{ Ever heard of an illness called malaria } & No & $0(0)$ & $1(0.01)$ \\
\hline & Yes & 179(98) & 182(98) \\
\hline \multirow[t]{2}{*}{ Cause of malaria } & Mosquito & 159(87) & 173(94) \\
\hline & Other ${ }^{a}$ & 153(84) & 143(78) \\
\hline \multirow[t]{3}{*}{ Knew malaria preventability } & Don't know & $1(0.5)$ & $0(0)$ \\
\hline & No & $3(1.6)$ & $0(0)$ \\
\hline & Yes & 181(98) & 182(98) \\
\hline \multirow[t]{6}{*}{ Prevention ways mentioned } & Bed net & 169(93) & 174(94) \\
\hline & Avoid mosquito bite & $19(10)$ & $25(14)$ \\
\hline & Take preventive medication & $40(22)$ & $54(29)$ \\
\hline & Indoor residual spraying & $39(22)$ & $58(31)$ \\
\hline & Filling stagnant water & $48(27)$ & $48(28)$ \\
\hline & Other ${ }^{b}$ & $90(50)$ & $68(37)$ \\
\hline
\end{tabular}


another endemic malaria areas, self-reported bed net use, household bed net possession, and household bed net ratio were not statistically significantly associated with malaria infection (Table 4).

\section{Discussion}

In this study, being male, 15 and above years of age, staying outdoors at night, bed net sharing with more than 3 persons, and proximity to stagnant water were the determinants of malaria infection. However,

Table 4 Determinants of malaria infection in Dembia District, northwest Ethiopia, $2016(N=370)$

\begin{tabular}{|c|c|c|c|c|}
\hline Variables & $\begin{array}{l}\text { Cases } \\
(N=185)\end{array}$ & $\begin{array}{l}\text { Controls } \\
(N=185)\end{array}$ & $\begin{array}{l}\text { COR (95 } \\
\% \mathrm{Cl})\end{array}$ & $\operatorname{AOR}(95 \% \mathrm{Cl})$ \\
\hline \multicolumn{5}{|l|}{ Sex } \\
\hline Male & 137 & 85 & $3.4(2.2-5.2)$ & $2.2(1.2-3.9)^{a}$ \\
\hline Female & 48 & 100 & 1 & 1 \\
\hline \multicolumn{5}{|c|}{ Outdoor activities at night } \\
\hline Yes & 82 & 31 & $4.0(2.4-6.4)$ & $5.7(2.5-12.7)^{a}$ \\
\hline No & 103 & 154 & 1 & 1 \\
\hline \multicolumn{5}{|c|}{ Travel history in the past 2 weeks to other malaria endemic areas } \\
\hline Yes & 35 & 11 & $3.7(1.8-7.5)$ & $1.6(0.5-5.0)$ \\
\hline No & 150 & 174 & 1 & 1 \\
\hline \multicolumn{5}{|c|}{ Sleeping outdoors at night } \\
\hline Yes & 29 & 8 & $4.1(1.8-9.3)$ & $0.9(0.2-3.2)$ \\
\hline No & 156 & 177 & 1 & 1 \\
\hline \multicolumn{5}{|c|}{ Bed net use } \\
\hline Yes & 137 & 153 & $0.4(0.2-1.0)$ & $0.6(0.2-1.7)$ \\
\hline No & 17 & 8 & 1 & 1 \\
\hline \multicolumn{5}{|c|}{ Household bed net possession } \\
\hline Yes & 152 & 161 & $0.7(0.4-1.2)$ & $0.83(0.8-2.8)$ \\
\hline No & 33 & 24 & 1 & 1 \\
\hline \multicolumn{5}{|c|}{ Proximity to stagnant water body } \\
\hline Yes & 58 & 34 & $1.5(1.0-2.4)$ & $2.7(1.3-5.4)^{a}$ \\
\hline No & 127 & 151 & 1 & 1 \\
\hline \multicolumn{5}{|c|}{ Proximity to temporary river body } \\
\hline Yes & 127 & 109 & $1.5(1.0-2.3)$ & $1.1(0.6-2.0)$ \\
\hline No & 58 & 76 & 1 & 1 \\
\hline \multicolumn{5}{|c|}{ Persons sharing a bed net } \\
\hline$\leq 2$ & 98 & 51 & $3.9(2.4-6.2)$ & $3.9(2.0-7.7)^{\mathrm{a}}$ \\
\hline$\geq 3$ & 54 & 109 & 1 & 1 \\
\hline \multicolumn{5}{|c|}{ Age (in year) } \\
\hline$\leq 4$ & 10 & 1 & 1 & 1 \\
\hline $5-14$ & 37 & 1 & $0.3(0.02-4.7)$ & $0.6(0.3-6.2)$ \\
\hline$\geq 15$ & 138 & 183 & $13.3(1.7-4.8)$ & $18(2.1-161.5)^{a}$ \\
\hline
\end{tabular}

ownership and use of ITN were not statistically significant predictors for malaria infection.

In our study, males were more affected by malaria infection than females. This result is in line with those of studies done in Oromia Regional State, Ethiopia, and Eastern Rwanda [12, 13]. This might be so because agriculture is the main occupation and sleeping, and staying outdoors at night is common. Thus, males are more exposed to anopheles mosquito bites. The other possible reason might be that males are particularly less likely to use bed nets even when nets are available [13].

The finding showed that individuals sharing a bed net with more than 3 persons were found to be at more risk for malaria infection than those sharing a net with two other persons. The finding is supported by that of a study done in Laos [14]. In addition, outdoor activity is associated with malarial illness in this study; it is possible that bed nets were not used during outdoors, decreasing their effectiveness in preventing malaria illness. Bed net possession and use is the commonest method of the prevention of malaria infection $[9,15]$. In this study, however, it had no statistically significant association with malaria infection contrary to findings of other studies $[12,16]$. In this context, these results could derive from a combination of factors, such as the conditions of nets [17], vector resistance issues [18-21], and sleeping sites [22].

Contrary to the findings of other works, IRS was not significantly associated with malaria protection in our study. This may be due to the fact that few households had IRS in the previous 6 months. In addition, it may be due to vector resistance to spray chemicals $[18,23]$. Besides, after 5 months, IRS is insufficient to kill resistant mosquitoes [24].

In this study, malaria infection was more widespread among people aged above 15 years. This result is supported by that of a study done in Machinga district, Malawi and WHO malaria report [12, 25]. This might be due to the fact that productive age groups are usually engaged in outdoor activities at dawn and dusk, increase their exposure $[13,26]$. Similarly, it is found that outdoor activity at night is one of the significant risk factors for malaria infection in the area. However, this is contrary to the findings in Zimbabwe [26], where individuals below 5 years of age were more at risk of malaria infections. This may be due to cultural differences in that younger individuals are subject to night time outdoor activities in the study area (in Zimbabwe) with no habit of using repellents.

Stagnant water bodies (marshy areas), which are risk factors for malaria infections, are one of the places where malaria vectors breed [27]. Consequently, people near stagnant water bodies are at higher risk for malarial disease than their counterparts. 


\section{Limitation of the study}

As a case-control study, our work is prone to selection and recall biases. Besides, LLIN use was reported rather than observed and might have limited the generalizability of the findings.

\section{Conclusion}

Despite the high proportion of bed net possession and self-reported utilization, being male, 15 and above years of age, staying outdoors at night, bed net sharing with more than 3 persons and proximity to stagnant water were the determinants of malaria infection. However, the study identified neither household bed net possession nor self-reported bed net use control measures to be independently associated with malaria infection. Therefore, we focused on men, outdoor activities, and the control of the breeding of the malaria vector on stagnant water bodies, and other bed net distributions to family members in this district to prevent malaria infections.

\section{Abbreviations}

ACT: Artemesinin-based combination therapies; FMOH: Federal Ministry of Health; IRS: Indoor residual spraying; LLNs: Long lasting insecticidal nets; MIS: Malaria indicator survey; RDT: Rapid diagnostics tests

\section{Acknowledgments}

Authors would like to thank the University of Gondar for the ethical clearance. We would also like to thank the Amhara Regional State Health Bureau, North Gondar Zone Health Department, Dembia Woreda Health Office, and the health centers for the permission, and participants for their cooperation.

\section{Funding}

The authors declare that there is no funding source.

\section{Availability of data and materials}

Full data set and materials pertaining to this study can be obtained from the correspondence author on reasonable request.

\section{Authors' contributions}

AS, MT, and FB designed the proposal. FA acquired the data, performed the analysis and drafted the manuscript. All authors discussed the results and implications and commented on the manuscript at all stages. All authors contributed extensively to the work presented in this paper. All authors read and approved the final manuscript.

\section{Ethics approval and consent to participate}

The study was conducted after ethical clearance was given by the Research and Ethics Committee of the University of Gondar. Informed written consent was obtained from all adults and parents, or guardians for enrollment in the study. The confidentiality of the information collected from was maintained by not taking participants' names.

\section{Consent for publication}

Not applicable.

\section{Competing interests}

The authors declare that they have no competing interests.

\section{Publisher's Note}

Springer Nature remains neutral with regard to jurisdictional claims in published maps and institutional affiliations.

\section{Author details}

${ }^{1}$ Amhara Regional Health Bureau, Bahir Dar, Ethiopia. ${ }^{2}$ Department of Epidemiology and Biostatistics, College of Medicine and Health Sciences, University of Gondar, Gondar, Ethiopia. ${ }^{3}$ Clinical Psychology and Counseling Unit, University of Gondar Specialized Hospital, Gondar, Ethiopia.

${ }^{4}$ Departement of Human Nutrition, College of Medicine and Health Sciences, University of Gondar, Gondar, Ethiopia.

Received: 12 November 2017 Accepted: 25 March 2018

Published online: 11 April 2018

\section{References}

1. Barber BE, Rajahram GS, Grigg MJ, William T, Anstey NM. World malaria report: time to acknowledge Plasmodium knowlesi malaria. Malar J. 2017; 16(1):135.

2. World Health Organization. World malaria report 2015: World Health Organization; 2016. http://apps.who.int/iris/bitstream/handle/10665/200018/ 9789241565158_eng.pdf.

3. Siraj AS, Santos-Vega M, Bouma MJ, Yadeta D, Ruiz Carrascal D, Pascual M. Altitudinal changes in malaria incidence in highlands of Ethiopia and Colombia. Science. 2014;343(6175):1154-8.

4. Alemu A, Fuehrer HP, Getnet G, Kassu A, Getie S, Noedl H. Comparison of Giemsa microscopy with nested PCR for the diagnosis of malaria in North Gondar, north-West Ethiopia. Malar J. 2014;13:174.

5. Alemu A, Muluye D, Mihret M, Adugna M, Gebeyaw M. Ten year trend analysis of malaria prevalence in kola Diba, North Gondar, Northwest Ethiopia. Parasit Vectors. 2012;5:173.

6. Toyama Y, Ota M, Molla G, Beyene BB. Sharp decline of malaria cases in the Burie Zuria, Dembia, and Mecha districts, Amhara region, Ethiopia, 20122014: descriptive analysis of surveillance data. Malar J. 2016;15(1):104.

7. Population Census Commission: Summary and statistical report of the 2007 population and housing census: population size by age and sex. 2008.

8. Jima D, Wondabeku M, Alemu A, Teferra A, Awel N, Deressa W, Adissie A, Tadesse Z, Gebre T, Mosher AW, et al. Analysis of malaria surveillance data in Ethiopia: what can be learned from the integrated disease surveillance and response system? Malar J. 2012;11:330.

9. Ntonifor NH, Veyufambom S. Assessing the effective use of mosquito nets in the prevention of malaria in some parts of Mezam division, Northwest Region Cameroon. Malar J. 2016;15(1):390.

10. Weldegebriel ZB, Amphune BE. Livelihood resilience in the face of recurring floods: an empirical evidence from Northwest Ethiopia. Geoenvironmental Disasters. 2017:4(1):10.

11. Federal demographic repblic of Ethiopia ministry of health National Malaria Indicator Survey 2011 Technical Summary. SEP; 2012. http://www.ephi.gov. et/images/downloads/2011ethiopiamistechsummary.pdf.

12. Yukich JO, Taylor C, Eisele TP, Reithinger R, Nauhassenay H, Berhane $Y$, Keating J. Travel history and malaria infection risk in a low-transmission setting in Ethiopia: a case control study. Malar J. 2013;12:33.

13. Kateera F, Ingabire CM, Hakizimana E, Rulisa A, Karinda P, Grobusch MP, Mutesa $L$, van Vugt $M$, Mens PF. Long-lasting insecticidal net source, ownership and use in the context of universal coverage: a household survey in eastern Rwanda. Malar J. 2015;14:390.

14. Nonaka D, Laimanivong S, Kobayashi J, Chindavonsa K, Kano S, Vanisaveth V, Yasuoka J, Phompida S, Jimba M. Is staying overnight in a farming hut a risk factor for malaria infection in a setting with insecticide-treated bed nets in rural Laos? Malar J. 2010;9:372.

15. Kesteman $T$, Randrianarivelojosia $M$, Raharimanga $V$, Randrianasolo L, Piola $P$, Rogier C. Effectiveness of malaria control interventions in Madagascar: a nationwide case-control survey. Malar J. 2016;15:83.

16. Mathanga DP, Tembo AK, Mzilahowa T, Bauleni A, Mtimaukenena K, Taylor TE, Valim C, Walker ED, Wilson ML. Patterns and determinants of malaria risk in urban and peri-urban areas of Blantyre, Malawi. Malar J. 2016;15(1):590.

17. Atieli FK, Munga SO, Ofulla AV, Vulule JM. The effect of repeated washing of long-lasting insecticide-treated nets (LLINs) on the feeding success and survival rates of Anopheles gambiae. Malar J. 2010;9(1):304.

18. Cohen JM, Smith DL, Cotter C, Ward A, Yamey G, Sabot OJ, Moonen B. Malaria resurgence: a systematic review and assessment of its causes. Malar J. $2012 ; 11: 122$ 
19. Djouaka RJ, Atoyebi SM, Tchigossou GM, Riveron JM, Irving H, Akoton R, Kusimo MO, Bakare AA, Wondji CS. Evidence of a multiple insecticide resistance in the malaria vector Anopheles funestus in south West Nigeria. Malar J. 2016;15(1):565.

20. Mourou JR, Coffinet T, Jarjaval F, Pradines B, Amalvict R, Rogier C, Kombila $M$, Pages F. Malaria transmission and insecticide resistance of Anopheles gambiae in Libreville and Port-Gentil, Gabon. Malar J. 2010;9:321.

21. Quinones ML, Norris DE, Conn JE, Moreno M, Burkot TR, Bugoro H, Keven $\mathrm{JB}$, Cooper $\mathrm{R}$, Yan $\mathrm{G}$, Rosas $\mathrm{A}$, et al. Insecticide resistance in areas under investigation by the international centers of excellence for malaria research: a challenge for malaria control and elimination. Am J Trop Med Hyg. 2015; 93(3 Suppl):69-78.

22. Iwashita H, Dida G, Futami K, Sonye G, Kaneko S, Horio M, Kawada H, Maekawa Y, Aoki Y, Minakawa N. Sleeping arrangement and house structure affect bed net use in villages along Lake Victoria. Malar J. 2010:9:176.

23. Asale A, Getachew Y, Hailesilassie W, Speybroeck N, Duchateau L, Yewhalaw D. Evaluation of the efficacy of DDT indoor residual spraying and longlasting insecticidal nets against insecticide resistant populations of Anopheles arabiensis Patton (Diptera: Culicidae) from Ethiopia using experimental huts. Parasites Vectors. 2014;7(1):131.

24. Protopopoff N, Matowo J, Malima R, Kavishe R, Kaaya R, Wright A, West PA, Kleinschmidt I, Kisinza W, Mosha FW, et al. High level of resistance in the mosquito Anopheles gambiae to pyrethroid insecticides and reduced susceptibility to bendiocarb in North-Western Tanzania. Malar J. 2013;12:149.

25. World Health Organization: World malaria report 2014: summary. 2015

26. Mugwagwa N, Mberikunashe J, Gombe NT, Tshimanga M, Bangure D, Mungati M. Factors associated with malaria infection in Honde valley, Mutasa district, Zimbabwe, 2014: a case control study. BMC Res Notes. 2015;8:829.

27. Deribew A, Birhanu Z, Sena L, Dejene T, Reda AA, Sudhakar M, Alemseged F, Tessema F, Zeynudin A, Biadgilign S, et al. The effect of household heads training about the use of treated bed nets on the burden of malaria and anaemia in under-five children: a cluster randomized trial in Ethiopia. Malar J. 2012;11:8

\section{Submit your next manuscript to BioMed Central and we will help you at every step:}

- We accept pre-submission inquiries

- Our selector tool helps you to find the most relevant journal

- We provide round the clock customer support

- Convenient online submission

- Thorough peer review

- Inclusion in PubMed and all major indexing services

- Maximum visibility for your research

Submit your manuscript at www.biomedcentral.com/submit 